\title{
The elusive etiology of autism: nature and nurture?
}

\author{
Lane Strathearn ${ }^{1,2,3 *}$ \\ The Meyer Center for Developmental Pediatrics, Department of Pediatrics, Baylor College of Medicine/Texas Children's Hospital, Houston, TX, USA \\ 2 Human Neuroimaging Laboratory, Department of Neuroscience, Baylor College of Medicine, Houston, TX, USA \\ ${ }^{3}$ School of Medicine, The University of Queensland, QLD, Australia \\ *Correspondence: lanes@bcm.edu
}

Autism spectrum disorder (ASD) is a serious neurodevelopmental disorder encompassing severe deficits in social communication and language development, and associated with repetitive, stereotypic behaviors. It is estimated that as many as 1 in 150 children in the United States are affected (Centers for Disease Control and Prevention, 2007).

Over the past decade, we have witnessed remarkable scientific advancements in our ability to explore the origins and manifestations of autism, using tools such as genome-wide microarray analyses, functional neuroimaging and automated eye tracking. Yet, despite these innovations, we have failed to uncover a core psychobiological deficit for autism. Without such an understanding, treatment options are limited to various combinations of childdirected therapy, with minimal data supporting effectiveness (Ospina et al., 2008). With the dramatic rise in the number of children diagnosed with autism (Blaxill, 2004) comes an escalating burden for schools, governments and society to provide intensive and costly services. Clearly, understanding the etiology of autism is of paramount importance.

\section{THE ETIOLOGY OF AUTISM - NATURE VS. NURTURE}

Over the past 60 years, the pendulum of public and scientific opinion on the etiology of autism has swung between two extreme positions: (1) that autism is caused by some specific genetic abnormality, spawning a search for the "autism gene", and (2) that autism is the result of some specific environmental factor or condition, including a "lack of maternal warmth" (Kanner, 1949). Although the etiology of autism has remained elusive, the evidence to date has strongly refuted both of these extreme positions.

As one of the first to systematically examine and describe a cohort of children with autism, Kanner hypothesized that these children were both genetically predisposed to develop autism, but also affected by parenting behavior. In his original 1943 paper, he stated that they "come into the world with innate inability to form the usual, biologically provided affective contact with people", while he questioned "whether or to what extent [parenting behaviors and characteristics] contributed to the condition of the children" (Kanner, 1943). Based on his observations of the families of children with autism, he later suggested that autism may be caused by a "genuine lack of maternal warmth" (Kanner, 1949). However, this idea was directly confronted by a psychologist named Bernard Rimland (who was also the parent of an ASD child) in his book, "Infantile Autism: The Syndrome and its Implications for a Neural Theory of Behavior" (Rimland, 1964). Herein he proposed a purely biological mechanism for the etiology of autism.

\section{NATURE: THE CONTRIBUTION OF GENETICS}

Over subsequent years, epidemiological studies have pointed to a genetic etiology of autism, with up to $60 \%$ concordance in monozygotic twins compared with $\sim 5 \%$ for dizygotic pairs (Bailey et al., 1995). Nevertheless, affected monozygotic twins did not exhibit similar autistic characteristics, any more so than dizygotic twins (Le et al., 1996), implying that non-genetic or epigenetic factors were also likely to be important.

Today, with the availability of genomewide array analyses, multiple genetic markers of autism susceptibility have been identified, such as genes encoding for neuronal cell-adhesion molecules (Wang et al., 2009) and copy number variations in surrounding regions (Glessner et al., 2009). However, these factors appear to explain only a small degree of variance (Geschwind, 2008; Sutcliffe, 2008). Other rare genetic disorders, such as Fragile X syndrome and tuberous sclerosis, have been associated with a higher rate of autism, although each possesses fundamentally different genetic abnormalities (Levitt and Campbell, 2009). One recently discovered functional class of autism-associated genes is regulated by neuronal activity, suggesting that both genetic variation and experience may contribute to the development of autism (Morrow et al., 2008). Thus, current models propose that multiple genetic, epigenetic and environmental factors may contribute to the etiology of autism (Geschwind, 2008).

\section{NURTURE: THE CONTRIBUTION OF SOCIAL ENVIRONMENT}

Even before the careful descriptions of ASD patients were published by Kanner and Asperger, isolated cases were reported of children exhibiting autistic features, who had been exposed to severe trauma or deprivation (Wolff, 2004). Harlow's studies of rhesus monkeys exposed to severe maternal deprivation also revealed behavioral characteristics resembling that of autism (Harlow and Harlow, 1972). In 1999, "quasi-autistic" traits were described in up to $12 \%$ of Romanian orphans exposed to severe deprivation, who were later adopted in the UK, with symptoms related to the age of adoption (Rutter et al., 1999). At age 4, these children were clinically indistinguishable from children with "typical" autism, although differences in behavior and response to treatment emerged over time (Rutter et al., 2007). Rutter and colleagues proposed that "social privation might also impair developmental programming for aspects of psychological functioning relevant to the genesis of autism".

Many congenitally blind children also exhibit characteristics of autism, to varying degrees. A spectrum of autistic features has been observed in visually impaired children (Hobson and Bishop, 2003), with autistic features significantly correlated with severity of blindness and mental retardation (Mukaddes et al., 2007). This leads to the question: are there mechanisms which may account for the observed relationship 
between sensory deprivation, congenital blindness and autism?

\section{FACE PROCESSING, OXYTOCIN AND AUTISM}

Both Dawson (2008) and Schultz (2005) have hypothesized that basic deficits in social perception may underlie many of the other developmental and behavioral abnormalities seen in autism. They hypothesize that a set of defining experiences early in development may critically affect the development of multiple neural systems. Just as visual deprivation during a critical period of development may result in long-term visual impairment (Wiesel and Hubel, 1965), it is proposed that social deprivation - either externally or internally derived - may contribute to impairment in social development.

While face processing is a key factor in the development of social perception, it is severely impaired in autistic children. Numerous studies have noted face processing deficits using ERP (Dawson et al., 2005b), as well as an impaired ability to recognize faces (Klin et al., 1999) and to fixate on the eyes of others (Jones et al., 2008). Functional MRI studies have demonstrated reduced activation of the fusiform face area when viewing or discriminating faces of unknown adults (Pierce and Redcay, 2008; Schultz, 2005). While infants possess an innate perceptual bias for face-like shapes, the capacity to distinguish facial features develops during the first year of life (Cassia et al., 2006; Gliga and Csibra, 2007). It is proposed that some cases of ASD may result from a deficit in exposure to contingent, socially responsive facial expressions during a sensitive period of social development.

Oxytocin (OT), a neuropeptide associated with social memory and learning, enhances direct eye gaze and the ability to identify and remember faces, as seen in blinded placebo-controlled trials (Guastella et al., 2008; Savaskan et al., 2008). OT receptor expression also appears to be programmed by early life experience via epigenetic mechanisms (Champagne et al., 2001,2006), with decreased expression seen in the brains of animals who received lower levels of contingent maternal care in infancy. OT deficits in humans have also been implicated in autism, with reduced peripheral OT levels observed in autistic subjects (Green et al.,
2001; Modahl et al., 1998). Furthermore, intravenous OT produces a reduction in stereotypic behaviors in adult ASD subjects (Hollander et al., 2003). Together, these studies suggest that OT may play an important role in promoting social perception, while deficits may be associated with the development of autism.

\section{CONCLUSIONS: NATURE AND NURTURE?}

As originally observed by Kanner, and confirmed in numerous recent studies, parents of autistic children often exhibit similar characteristics, including face processing deficits, aloofness, behavioral rigidities, and pragmatic language deficits (Dawson et al., 2005a; Piven et al., 1994, 1997). While these characteristics have generally been ascribed to a genetically based "broad autism phenotype", it is also possible, as Kanner first proposed, that "the patient, endowed with an innate disability to relate to people, is further influenced adversely by the parents' emotional detachment" (Kanner, 1965). Is it possible, for example, that the parents' face processing deficits may be causally linked to the deficits seen in their children? Furthermore, could "institutionalization" of infants, in the form of prolonged early non-parental care, be an additional risk factor for autism? As our understanding of epigenetics evolves, the answers may lie in how the social environment influences gene expression and social development.

Thus, despite detours along the way, we return to the original observations of Kanner to propose that the true etiology of autism may incorporate both nature and nurture genetically determined predispositions and the cumulative effects of exposure to adverse or atypical social environments.

\section{REFERENCES}

Bailey, A., Le Couteur, A., Gottesman, I., Bolton, P., Simonoff, E., Yuzda, E., and Rutter, M. (1995). Autism as a strongly genetic disorder: evidence from a British twin study. Psychol. Med. 25, 63-77.

Blaxill, M. F. (2004). What's going on? The question of time trends in autism. Public Health Rep. 119, 536-551.

Cassia, V. M., Kuefner, D., Westerlund, A., and Nelson C. A. (2006). A behavioural and ERP investigation of 3-month-olds' face preferences. Neuropsychologia 44, 2113-2125.

Centers for Disease Control and Prevention. (2007). Morbidity and Mortality Weekly Report. Surveillance
Summaries, Vol. 56 (No. SS-1). Atlanta, GA, Coordinating Center for Health Information and Service, Centers for Disease Control and Prevention (CDC), U.S. Department of Health and Human Services.

Champagne, F., Diorio, J., Sharma, S., and Meaney, M. J. (2001). Naturally occurring variations in maternal behavior in the rat are associated with differences in estrogen-inducible central oxytocin receptors. Proc. Natl. Acad. Sci. USA 98, 12736-12741.

Champagne, F. A., Weaver, I. C. G., Diorio, J., Dymov, S., Szyf, M., and Meaney M. J. (2006). Maternal care associated with methylation of the estrogen receptor- $\alpha 1 b$ promoter and estrogen receptor- $\alpha$ expression in the medial preoptic area of female offspring. Endocrinology 147, 2909-2915.

Dawson, G. (2008). Early behavioral intervention, brain plasticity, and the prevention of autism spectrum disorder. Dev. Psychopathol. 20, 775-803.

Dawson, G., Webb, S. J., Wijsman, E., Schellenberg, G., Estes, A., Munson, J., and Faja, S. (2005a). Neurocognitive and electrophysiological evidence of altered face processing in parents of children with autism: implications for a model of abnormal development of social brain circuitry in autism. Dev. Psychopathol. 17, 679-697.

Dawson, G., Webb, S. J., and McPartland, J. (2005b). Understanding the nature of face processing impairment in autism: insights from behavioral and electrophysiological studies. Dev. Neuropsychol. 27, 403-424.

Geschwind, D. H. (2008). Autism: many genes, common pathways? Cell 135, 391-395.

Glessner, J. T., Wang, K., Cai, G., Korvatska, O., Kim, C. E., Wood, S., Zhang, H., Estes A., et al. (2009). Autism genome-wide copy number variation reveals ubiquitin and neuronal genes. Nature 459, 569-573.

Gliga, T., and Csibra, G. (2007). Seeing the face through the eyes: a developmental perspective on face expertise. Prog. Brain Res. 164, 323-339.

Green, L., Fein, D., Modahl, C., Feinstein, C., Waterhouse, L., and Morris, M. (2001). Oxytocin and autistic disorder: alterations in peptide forms. Biol. Psychiatry 50, 609-613.

Guastella, A. J., Mitchell, P. B., and Dadds, M. R. (2008). Oxytocin increases gaze to the eye region of human faces. Biol. Psychiatry 63, 3-5.

Harlow, H. F., and Harlow, H. K. (1972). The affectional systems. In Behaviour of Non-human Primates, A. Schrier, H. F. Harlow and F. Stollnitz, eds. New York, Academic Press.

Hobson, R. P., and Bishop, M. (2003). The pathogenesis of autism: insights from congenital blindness. Philos. Trans. R. Soc. Lond., B, Biol. Sci. 358, 335-344.

Hollander, E., Novotny, S., Hanratty, M., Yaffe, R., DeCaria, C. M., Aronowitz, B. R., and Mosovich, S. (2003). Oxytocin infusion reduces repetitive behaviors in adults with autistic and Asperger's disorders. Neuropsychopharmacology 28, 193-198.

Jones, W., Carr, K., and Klin, A. (2008). Absence of preferential looking to the eyes of approaching adults predicts level of social disability in 2-year-old toddlers with autism spectrum disorder. Arch. Gen. Psychiatry 65, 946-954.

Kanner, L. (1943). Autistic disturbances of affective contact. Nerv. Child 2, 217-250. 
Kanner, L. (1949). Problems of nosology and psychodynamics of early infantile autism. Am. J. Orthopsychiatry 19, 416-426.

Kanner, L. (1965). Infantile autism and the schizophrenias. Behav. Sci. 10, 412-420.

Klin, A., Sparrow, S. S., de Bildt, A., Cicchetti, D. V. Cohen, D. J., and Volkmar, F. R. (1999). A normed study of face recognition in autism and related disorders. J. Autism Dev. Disord. 29, 499-508.

Le, C. A., Bailey, A., Goode, S., Pickles, A., Robertson, S., Gottesman, I., and Rutter, M. (1996). A broader phenotype of autism: the clinical spectrum in twins. J. Child Psychol. Psychiatry 37, 785-801.

Levitt, P., and Campbell, D. B. (2009). The genetic and neurobiologic compass points toward common signaling dysfunctions in autism spectrum disorders. J. Clin. Invest. 119, 747-754.

Modahl, C., Green, L., Fein, D., Morris, M., Waterhouse, L., Feinstein, C., and Levin, H. (1998). Plasma oxytocin levels in autistic children. Biol. Psychiatry 43, 270-277.

Morrow, E. M., Yoo, S. Y., Flavell, S. W., Kim, T. K., Lin, Y., Hill, R. S., Mukaddes, N. M., Balkhy, S., et al. (2008). Identifying autism loci and genes by tracing recent shared ancestry. Science 321 , 218-223.

Mukaddes, N. M., Kilincaslan, A., Kucukyazici, G., Sevketoglu, T., and Tuncer, S. (2007). Autism in visually impaired individuals. Psychiatry Clin. Neurosci. 61, 39-44.
Ospina, M. B., Krebs Seida, J., Clark, B., Karkhaneh, M., Hartling, L., Tjosvold, L., Vandermeer, B., and Smith, V. (2008). Behavioural and developmental interventions for autism spectrum disorder: a clinical systematic review. PLoS ONE 3, e3755.

Pierce, K., and Redcay, E. (2008). Fusiform function in children with an autism spectrum disorder is a matter of “who". Biol. Psychiatry 64, 552-560.

Piven, J., Palmer, P., Landa, R., Santangelo, S., Jacobi, D. and Childress, D. (1997). Personality and language characteristics in parents from multiple-incidence autism families. Am. J. Med. Genet. 74, 398-411.

Piven, J., Wzorek, M., Landa, R., Lainhart, J., Bolton, P., Chase, G. A., and Folstein, S. (1994). Personality characteristics of the parents of autistic individuals. Psychol. Med. 24, 783-795.

Rimland, B. (1964). Infantile Autism: The Syndrome and its Implications for a Neural Theory of Behavior. New York, Appleton-Century-Crofts.

Rutter, M., Andersen-Wood, L., Beckett, C. Bredenkamp, D., Castle, J., Groothues, C., Kreppner, J., Keaveney, L., et al. (1999). Quasi-autistic patterns following severe early global privation. English and Romanian Adoptees (ERA) Study Team. J. Child Psychol. Psychiatry 40, 537-549.

Rutter, M., Kreppner, J., Croft, C., Murin, M., Colvert, E. Beckett, C., Castle, J., and Sonuga-Barke, E. (2007). Early adolescent outcomes of institutionally deprived and non-deprived adoptees. III. Quasi-autism. J. Child Psychol. Psychiatry 48, 1200-1207.
Savaskan, E., Ehrhardt, R., Schulz, A., Walter, M., and Schachinger, H. (2008). Post-learning intranasal oxytocin modulates human memory for facial identity. Psychoneuroendocrinology 33, 368-374.

Schultz, R. T. (2005). Developmental deficits in social perception in autism: the role of the amygdala and fusiform face area. Int. J. Dev. Neurosci. 23, 125-141. Sutcliffe, J.S. (2008). GENETICS: insights into the pathogenesis of autism. Science 321, 208-209.

Wang, K., Zhang, H., Ma, D., Bucan, M., Glessner, J. T., Abrahams, B. S., Salyakina, D., Imielinski, M., et al. (2009). Common genetic variants on 5p14.1 associate with autism spectrum disorders. Nature 459, 528-533.

Wiesel, T. N., and Hubel, D. H. (1965). Comparison of the effects of unilateral and bilateral eye closure on cortical unit responses in kittens. J. Neurophysiol. 28, 1029-1040.

Wolff, S. (2004). The history of autism. Eur. Child Adolesc. Psychiatry 13, 201-208.

Received: 01 July 2009; published: 20 July 2009.

Citation: Front. Behav. Neurosci. (2009) 3:11. doi: 10.3389/neuro.08.011.2009

Copyright (C) 2009 Strathearn. This is an open-access article subject to an exclusive license agreement between the authors and the Frontiers Research Foundation, which permits unrestricted use, distribution, and reproduction in any medium, provided the original authors and source are credited. 